\title{
Neonatal Screening
}

ISSN 2409-515X

www.mdpi.com/journal/neonatalscreening

Review

\section{Newborn Screening for Glutaric Aciduria Type I: Benefits and limitations}

\author{
Jana Heringer, Nikolas Boy, Peter Burgard, Jürgen G. Okun and Stefan Kölker * \\ University Children's Hospital Heidelberg, Clinic 1, Division of Neuropediatrics and Metabolic Medicine, \\ 69120 Heidelberg, Germany; E-Mail: Jana.Heringer@med.uni-heidelberg.de (J.H.); \\ Nikolas.Boy@med.uni-heidelberg.de (N.B.); Peter.Burgard@med.uni-heidelberg.de (P.B.); \\ JuergenGuenther.Okun@med.uni-heidelberg.de (J.G.O.)
}

* Author to whom correspondence should be addressed; E-Mail: Stefan.Koelker@med.uni-heidelberg.de; Tel.: +49-6221-56-4002; Fax: +49-6221-56-5565.

Academic Editor: Ralph Fingerhut

Received: 22 April 2015 / Accepted: 30 June 2015 / Published: 10 July 2015

\begin{abstract}
More than 15 years ago glutaric aciduria type I has been included in newborn screening programmes and pilot studies evaluating the potential benefit of early diagnosis and start of metabolic treatment for patients with this disease have been initiated. At that time many important questions on epidemiology, diagnostic quality, natural history, treatment, and cost effectiveness were not sufficiently answered. In particular, it was rather unknown whether early treatment improves the outcome. After implementation of glutaric aciduria type I in an increasing number of countries, and with careful evaluation of disease course and impact of early treatment, there is now solid evidence that affected individuals do have substantial benefit and that newborn screening for this disease is a cost-effective diagnostic intervention. Despite this success, there are still limitations concerning diagnostic sensitivity for patients with a low excreting phenotype and knowledge on longterm disease outcome. In conclusion, it has become evident that tandem mass spectrometrybased newborn screening for glutaric aciduria type I is a powerful and cost-effective tool to prevent the manifestation of prognostically-relevant movement disorders in the majority of early diagnosed patients.
\end{abstract}

Keywords: glutaric aciduria type I; newborn screening; tandem mass spectrometry; glutarylcarnitine; guideline; cost-effectiveness 


\section{Introduction}

Glutaric aciduria type I (GA-I) is a rare inherited disorder of L-lysine, L-hydroxylysine and L-tryptophan metabolism first described in 1975 [1], with an overall estimated prevalence of 1 in 100,000 newborns [2,3]. High-risk populations with a prevalence of up to 1 in 300 newborns have been identified. This includes the Amish Community in Lancaster County, Pennsylvania, USA [4], the Oji-Cree First Nations in Western Ontario and Manitoba, Canada [5], the Lumbee in North Carolina, USA [6], the Irish Travellers in Ireland and the United Kingdom [7], and indigenous South Africans [8].

GA-I is caused by two pathogenic mutations in the GCDH gene which consists of 11 exons $(7 \mathrm{~kb})$ and is located on 19p13.2 [9]. More than 200 disease-causing mutations have been identified so far $[10,11]$; most of them are private. The most frequent mutation in Europe is p.Arg402Trp accounting for $10 \%-20 \%$ of all alleles. Other mutations are predominantly or even exclusively found in distinct populations such as p.Ala421Val in the Amish Community as well as Southern parts of Germany and Switzerland, the original settlement area of the Amish, IVS1 $+5 \mathrm{G}>\mathrm{T}$ in the Oji-Cree First Nations [12], p.Pro248Leu and p.Glu365Lys in Turkey [3], and p.Arg227Pro and p.Val400Met in Spain [13].

Inherited deficiency of glutaryl-CoA dehydrogenase, a mitochondrial flavoprotein which catalyzes the oxidative decarboxylation of glutaryl-CoA to crotonyl-CoA in the catabolic pathways of L-lysine, L-tryptophan and L-hydroxylysine, causes cerebral accumulation of glutaric acid (GA), 3-hydroxyglutaric acid (3-OH-GA) and glutarylcarnitine (C5DC). These metabolites can be detected in body fluids by quantitative gas chromatography/mass spectrometry (GA, 3-OH-GA) or tandem mass spectrometry (C5DC). Two biochemical subgroups, termed high and low excretors, have been delineated [14]. High excretors show a (near) loss of GCDH activity and high concentrations of GA (above $100 \mathrm{mmol} / \mathrm{mol}$ creatinine), whereas low excreting patients with GCDH residual activity of up to $30 \%$ urinary GA excretion is below $100 \mathrm{mmol} / \mathrm{mol}$ creatinine and in some patients is (intermittently) normal. The excretion of 3-OH-GA in both groups is less variable.

About $80 \%-95 \%$ of untreated patients are thought to develop a complex, irreversible movement disorder with predominant dystonia superimposing on truncal hypotonia [15-17] most often following an acute encephalopathic crises precipitated by intercurrent febrile illness, immunization or postsurgical metabolic stress during a defined period in infancy (mostly between age 3-36 months). Notably, some patients show an insidious onset of movement disorder without preceding encephalopathic crises [13,16,18]. In all dystonic patients striatal degeneration is the common neuropathological and neuroradiological finding [19,20]. Strikingly, untreated high and low excretors have the same risk of striatal degeneration and, therefore, low excretors should not be mistaken as a "mild" disease variant [16]. Striatal degeneration usually starts in the dorsolateral aspects of the putamen and then spreads over the striatum in a ventromedial direction; three neuroradiologically defined stages-acute, sub-acute and chronic-have been delineated [18]. Morbidity and mortality is significantly increased in dystonic patients [16,21].

In addition to striatal pathology, patients also show a broad spectrum of extrastriatal abnormalities including temporal hypoplasia with concomitantly widening of anterior temporal and sylvian CSF spaces, pseudocysts, signal changes of substantia nigra, thalamus, nucleus dentatus, and supratentorial 
white matter [20]. Extrastriatal abnormalities follow a variable pattern; they could proceed but sometimes regress or even normalize with time. In contrast to striatal degeneration, clinical relevance of extrastriatal changes is still unclear [22].

Since GA-I patients do not present with pathognomonic signs or symptoms in the newborn period or infancy, the majority of them are missed in this age group. Therefore, only younger siblings of previously identified index patients have had a realistic change of early diagnosis and treatment before the start of tandem mass spectrometry-based newborn screening programmes [16].

\section{To Screen or not to Screen?}

In the late 1990s, pilot studies on newborn screening for GA-I were initiated in a few countries (Australia, Germany, some US states) and in known high-risk populations (USA: Amish, Republic or Ireland: Irish Travellers). Some important epidemiological, diagnostic, clinical, therapeutic, and economic questions could not be adequately addressed at that time. Therefore the Health Technology Assessment in the UK in 1997 concluded that "GA-I comes quite close to fulfilling the necessary criteria for newborn screening although there is some lack of information on the absolute incidence and natural history" [23] and that "there was reasonable evidence to support inclusion in extended neonatal screening of (...) glutaric aciduria type 1" [24].

With more than 15 years experience in newborn screening for GA-I, it has become evident that this diagnostic intervention is a powerful tool to prevent the manifestation of movement disorders in the majority of early diagnosed patients $[3,15,16,18]$. As a consequence, the American College of Clinical Genetics has recommended it for screening [25]. However, despite increasing evidence, not more than one third of European Union Member States has implemented GA-I in its national disease panel [26]. In the following, we will evaluate the benefit of existing newborn screening programmes for GA-I based on the original principles of early disease detection as outlined by Wilson and Jungner [27].

\subsection{Knowledge of the Disease}

As described above, GA-I causes significant health problems. About $80 \%-95 \%$ of untreated GA-I patients present with acute or insidious onset of a complex movement disorder with predominant dystonia during infancy and childhood (age range 3-36 months, peak 9-10 months) [15,16,28,29]. Symptomatic patients have a significantly reduced life expectancy [16,21]. Despite some variability in the clinical presentation among siblings, manifestation of a movement disorder has a high penetrance [3,16,30]. Importantly, high and low excretors share the same risk of developing a movement disorder. Therefore the genotype predicts the biochemical but not the clinical phenotype [16,31]. This intriguing finding is best explained by cerebral entrapment of toxic dicarboxylic acids due to cerebral de novo synthesis and very limited efflux transport of the blood-brain barrier for these metabolites [16,19,32,33]. Affected individuals usually remain asymptomatic or show mild reversible neurological signs, such as truncal hypotonia, during the first three months of life since neonatal onset is a rare finding in this disease [16,18,28]. Macrocephaly which is found in about $75 \%$ of patients is not specific for GA-I since it has a broad differential diagnoses and is found in 3\% of the normal population (by definition). Few patients with late-onset GA-I presenting with white matter abnormalities in MRI and a broad spectrum of (progressive) signs and symptoms 
(macrocephaly, headaches, hand tremor, impaired fine motor function, seizures, ataxia, psychiatric disease) have been described [20,34]. It remains to be elucidated whether this group reflects a specific disease variant or whether white matter changes in adolescent and adult patients are a common finding. The latter notion is supported by the observation that extrastriatal MRI changes are also found in early diagnosed and treated GA-I patients and that white matter changes might increase with age [20,22,35,36].

The major limitation in evaluating the clinical benefit of newborn screening for GA-I patients is the current knowledge on the long-term disease course. This is highlighted by two recent studies. Although GA-I was previously thought to exclusively affect the brain, this notion was challenged by recent observation of peripheral neuropathy [37] and chronic renal failure in adolescent and adult patients [38].

\subsection{Knowledge of the Test}

The diagnostic test is the determination of glutarylcarnitine (C5DC) concentration in dried blood spots [39-41]. C5DC can be detected in dried blood spot samples by its ion pair $\mathrm{m} / \mathrm{z} 388 \rightarrow \mathrm{m} / \mathrm{z} 85$ using tandem mass spectrometry. Therefore, C5DC can be included in tandem mass-spectrometry based newborn screening. GA-I should be considered in newborns with C5DC concentrations above the cut-off. Neonatal screening centres follow different strategies for defining and updating cut-offs for C5DC, and no standardized procedure for the setting of cut-off levels has yet been established worldwide $[42,43]$. Only until recently internal standards for newborn screening have not included a stable isotope of C5DC, the C5DC concentration has been calculated in relation to the internal standard of octanoylcarnitine (C8). This procedure has resulted in low specificity and low positive predictive value in the early days of C5DC screening. These problems can be overcome using multiple reaction monitoring (MRM, $m / z 388 \rightarrow m / z 85$ for butylated samples) [44], a combination of C5DC with other acylcarnitines and acylcarnitine ratios using data mining techniques [45], and two-tier strategies using C5DC and 3-hydroxyglutaric acid [2,44,45]. Despite improvement of the diagnostic quality of C5DC screening, there are reported cases of missed low excretors in the literature, but the exact number, however, is not known since newborn screening programmes often lack a tracking system. In the German newborn screening programme, three patients have been missed in about five million newborns. The majority of these patients have been missed during the start of extended newborn screening, highlighting that screening algorithms and cut-offs have been improved $[12,42,46]$. In highrisk populations with low excretors, mutation-based analysis might be considered as a more reliable strategy [12]. The overall sensitivity of C5DC screening in a mixed population is about 95\% [3]. A deuterium-labeled analytical standard for C5DC is recently available and the implementation in the panel of standards will likely improve quantification of C5CD in the future. However, a systematic evaluation of the new standard is still lacking.

False positive screening results may be due to glutaric aciduria type II (multiple acyl-CoA dehydrogenase deficiency), pseudoglutarylcarnitinemia (hydroxydecanoylcarnitine) in patients with medium chain acyl-CoA dehydrogenase deficiency [47], newborns with renal failure [48], and maternal GA-I $[49,50]$. Therefore, these diagnostic pitfalls should be considered for interpretation of positive C5DC screening results and for establishment of reasonable diagnostic algorithms [43]. 


\subsection{Treatment for Disease}

In analogy to other protein-dependent inherited metabolic diseases, metabolic treatment including low lysine diet, carnitine supplementation and intermittent emergency treatment with transient stop of protein intake, energy- and carbohydrate-rich meals or glucose infusions (with or without insulin) during episodes that are likely to induce catabolism (e.g., intercurrent infectious diseases) was introduced for GA-I patients [15,29,51]. A meta-analysis on 115 patients, most of them treated after the onset of motor symptoms, however, did not reveal any significant effect on disease course [28]. A cross-sectional study on 279 patients later on showed that carnitine supplementation slightly reduced the mortality of symptomatic patients [16]. Before GA-I was implemented into national screening programmes, however, there was only very limited evidence that metabolic treatment in asymptomatic newborns or infants could improve the disease course in general and prevent manifestation of movement disorders [7,29,51]. In particular, it remained doubtful whether dietary treatment was beneficial [18]. After the start of newborn screening programmes and prospective follow-up studies in Europe, North America, Asia and Australia there is now increasing evidence that diagnosis and start of treatment during the newborn period has helped to significantly reduce the onset of a complex movement disorder in infancy and childhood and thus to improve the short-term outcome of GA-I patients (Table 1).

Table 1. Newborn screening in combination with early start of metabolic treatment improves the neurological outcome of patients with glutaric aciduria type I (selection of studies).

\begin{tabular}{|c|c|c|c|}
\hline Ref. & Country (State) & $\begin{array}{c}\text { Patients } \\
\quad N\end{array}$ & $\begin{array}{c}\text { Asymptomatic patients * } \\
N(\%)\end{array}$ \\
\hline [52] & Australia (New South Wales) & 7 & $6(86 \%)$ \\
\hline [53] & Australia (Victoria) & 7 & $6(86 \%)$ \\
\hline [42] & Germany & $\begin{array}{c}\text { Total: } 52 \\
\text { Adherence to guideline: } 37\end{array}$ & $\begin{array}{c}\text { Total: } 40(77 \%) \\
\text { Adherence to guideline: } 35(95 \%)\end{array}$ \\
\hline [54] & Japan & 4 & $4(100 \%)$ \\
\hline [55] & USA (Pennsylvania) & $\begin{array}{c}\text { Total: } 43 \\
\text { Cohort 1990-2005: 31; } \\
\text { Cohort 2006-2011: } 12 \\
\end{array}$ & $\begin{array}{c}\text { Total: } 31(72 \%) \\
\text { Cohort 1990-2005: } 19(61 \%) ; \\
\text { Cohort 2006-2011: } 12(100 \%)\end{array}$ \\
\hline [56] & USA (Utah) & 10 & $7(70 \%)$ \\
\hline [57] & Taiwan & 6 & $4(67 \%)$ \\
\hline [58] & Spain & 6 & $6(100 \%)$ \\
\hline
\end{tabular}

The prospective follow-up study in Germany showed that the absolute risk reduction for an acute encephalopathic crisis was 0.67 in the newborn screening group compared to symptomatic patients [3] and that the number needed to treat to prevent one acute encephalopathic crisis was 1.50 . This huge effect was confirmed in a second evaluation of the same cohort three years later [42]. The latter study demonstrated for the first time that both metabolic maintenance treatment with low lysine diet and carnitine supplementation and intermittent emergency treatment during infectious diseases and other 
potentially threatening episodes had a positive impact on the outcome. The best outcome was achieved in the group of neonatally-diagnosed patients who received metabolic maintenance and emergency treatment according to previously-published guidelines [59]. Since the guideline recommendations were developed by an international group of experts and were subsequently tested and approved, the currently available revised version of these recommendations should be regarded as best evidence available for the diagnosis, treatment and follow-up of GA-I patients [43]. The beneficial effect of newborn screening and combined metabolic treatment has been confirmed independently by other groups in different countries and national healthcare systems [52-58,60-62]. Based on this new therapy, options such as L-arginine supplementation aiming at reducing cerebral L-lysine influx and oxidation are currently discussed [55,62-65].

\subsection{Cost Considerations}

Cost-effectiveness of tandem mass spectrometry-based newborn screening for GA-I was recently assessed in Germany based on the results of the prospective follow-up study $[42,43,66]$. It was clearly shown using a Markov model that newborn screening for GA-I significantly reduced the number of disability adjusted life years (DALYs) by 3.7 and that it helped to save about 31,000 Euro per 100,000 screened newborns within a 20 year time horizon [66]. This study convincingly showed that implementation of GA-I to tandem mass spectrometry-based newborn screening programmes under conditions comparable to the national health care system in Germany is highly cost-effective.

\section{Conclusions}

More than 15 years after the start of first newborn screening pilot projects for GA-I, there is now convincing evidence from different countries and health systems that combination of early diagnosis via newborn screening and an early start of metabolic treatment has dramatically improved the neurological outcome and survival of patients with this disease. It is an excellent example how inclusion of a metabolic disease that does fulfill some but not all screening criteria to newborn screening pilot studies can improve the health outcome of affected individuals and how careful evaluation of the screening process, disease course, and economic parameters can help to fill initial gaps of knowledge. Despite this success, there are still limitations, including use of optimized combinations of newborn screening parameters to improve the diagnostic quality, continuation of long-term follow-up studies, and establishment of patient registries to identify long-term complications and to optimize therapy and therapy monitoring.

\section{Acknowledgments}

We are indebted to all patients and their families who have been willing to contribute to prospective observational follow-up study in Germany and to the European registry and network for intoxication type metabolic diseases (E-IMD) and to all colleagues who have helped to realize these projects. Furthermore, we are grateful to all experts and patient organisations for development, evaluation and review of the international guideline for glutaric aciduria type I. 
E-IMD has received funding from the European Commission (2011-2014), the Kindness for Kids Foundation e.V., Munich, Germany (2014-2016), and Dietmar Hopp Foundation e.V., St. Leon-Rot, Germany (since 2015). Guideline development was supported by the European Commission, Milupa Metabolics and Nutricia.

\section{Author Contributions}

Manuscript writing: Stefan Kölker and Jana Heringer. Contributions to the specific topics: Nikolas Boy (disease course and treatment), Peter Burgard (diagnostic process), Jürgen Günther Okun (metabolic analysis). Proofreading manuscript: all authors.

\section{Conflicts of Interest}

The authors declare no conflict of interest.

\section{References}

1. Goodman, S.I.; Markey, S.P.; Moe, P.G.; Miles, B.S.; Teng, C.C. Glutaric aciduria; a "new" disorder of amino acid metabolism. Biochem. Med. 1975, 12, 12-21.

2. Lindner, M.; Kölker, S.; Schulze, A.; Christensen, E.; Greenberg, C.R.; Hoffmann, G.F. Neonatal screening for glutaryl-coa dehydrogenase deficiency. J. Inherit. Metab. Dis. 2004, 27, 851-859.

3. Kölker, S.; Garbade, S.F.; Boy, N.; Maier, E.M.; Meissner, T.; Muhlhausen, C.; Hennermann, J.B.; Lucke, T.; Haberle, J.; Baumkotter, J.; et al. Decline of acute encephalopathic crises in children with glutaryl-coa dehydrogenase deficiency identified by newborn screening in germany. Pediatr. Res. 2007, 62, 357-363.

4. Morton, D.H.; Bennett, M.J.; Seargeant, L.E.; Nichter, C.A.; Kelley, R.I. Glutaric aciduria type i: A common cause of episodic encephalopathy and spastic paralysis in the amish of lancaster county, pennsylvania. Am. J. Med. Genet. 1991, 41, 89-95.

5. Haworth, J.C.; Dilling, L.A.; Seargeant, L.E. Increased prevalence of hereditary metabolic diseases among native indians in manitoba and northwestern ontario. Can. Med. Assoc. J. $=J$. Assoc. Med. Can. 1991, 145, 123-129.

6. Basinger, A.A.; Booker, J.K.; Frazier, D.M.; Koeberl, D.D.; Sullivan, J.A.; Muenzer, J. Glutaric acidemia type 1 in patients of lumbee heritage from north carolina. Mol. Genet. Metab. 2006, 88, 90-92.

7. Naughten, E.R.; Mayne, P.D.; Monavari, A.A.; Goodman, S.I.; Sulaiman, G.; Croke, D.T. Glutaric aciduria type i: Outcome in the republic of ireland. J. Inherit. Metab. Dis. 2004, 27, 917-920.

8. Van der Watt, G.; Owen, E.P.; Berman, P.; Meldau, S.; Watermeyer, N.; Olpin, S.E.; Manning, N.J.; Baumgarten, I.; Leisegang, F.; Henderson, H. Glutaric aciduria type 1 in south africa-high incidence of glutaryl-coa dehydrogenase deficiency in black south africans. Mol. Genet. Metab. 2010, 101, 178-182.

9. Greenberg, C.R.; Duncan, A.M.; Gregory, C.A.; Singal, R.; Goodman, S.I. Assignment of human glutaryl-coa dehydrogenase gene (gcdh) to the short arm of chromosome 19 (19p13.2) by in situ hybridization and somatic cell hybrid analysis. Genomics 1994, 21, 289-290. 
10. Goodman, S.I.; Stein, D.E.; Schlesinger, S.; Christensen, E.; Schwartz, M.; Greenberg, C.R.; Elpeleg, O.N. Glutaryl-coa dehydrogenase mutations in glutaric acidemia (type i): Review and report of thirty novel mutations. Hum. Mutat. 1998, 12, 141-144.

11. Zschocke, J.; Quak, E.; Guldberg, P.; Hoffmann, G.F. Mutation analysis in glutaric aciduria type i. J. Med. Genet. 2000, 37, 177-181.

12. Greenberg, C.R.; Prasad, A.N.; Dilling, L.A.; Thompson, J.R.; Haworth, J.C.; Martin, B.; Wood-Steiman, P.; Seargeant, L.E.; Seifert, B.; Booth, F.A.; et al. Outcome of the first 3-years of a DNA-based neonatal screening program for glutaric acidemia type 1 in manitoba and northwestern ontario, canada. Mol. Genet. Metab. 2002, 75, 70-78.

13. Busquets, C.; Merinero, B.; Christensen, E.; Gelpi, J.L.; Campistol, J.; Pineda, M.; Fernandez-Alvarez, E.; Prats, J.M.; Sans, A.; Arteaga, R.; et al. Glutaryl-coa dehydrogenase deficiency in spain: Evidence of two groups of patients, genetically, and biochemically distinct. Pediatr. Res. 2000, 48, 315-322.

14. Baric, I.; Wagner, L.; Feyh, P.; Liesert, M.; Buckel, W.; Hoffmann, G.F. Sensitivity and specificity of free and total glutaric acid and 3-hydroxyglutaric acid measurements by stableisotope dilution assays for the diagnosis of glutaric aciduria type i. J. Inherit. Metab. Dis. 1999, $22,867-881$.

15. Strauss, K.A.; Puffenberger, E.G.; Robinson, D.L.; Morton, D.H. Type i glutaric aciduria, part 1: Natural history of 77 patients. Am. J. Med. Genet. C Semin. Med. Genet. 2003, 121C, 38-52.

16. Kölker, S.; Garbade, S.F.; Greenberg, C.R.; Leonard, J.V.; Saudubray, J.M.; Ribes, A.; Kalkanoglu, H.S.; Lund, A.M.; Merinero, B.; Wajner, M.; et al. Natural history, outcome, and treatment efficacy in children and adults with glutaryl-coa dehydrogenase deficiency. Pediatr. Res. 2006, 59, 840-847.

17. Gitiaux, C.; Roze, E.; Kinugawa, K.; Flamand-Rouviere, C.; Boddaert, N.; Apartis, E.; Valayannopoulos, V.; Touati, G.; Motte, J.; Devos, D.; et al. Spectrum of movement disorders associated with glutaric aciduria type 1: A study of 16 patients. Mov. Disord.: Off. J. Mov. Disord. Soc. 2008, 23, 2392-2397.

18. Strauss, K.A.; Lazovic, J.; Wintermark, M.; Morton, D.H. Multimodal imaging of striatal degeneration in amish patients with glutaryl-coa dehydrogenase deficiency. Brain: J. Neurol. 2007, 130, 1905-1920.

19. Funk, C.B.; Prasad, A.N.; Frosk, P.; Sauer, S.; Kölker, S.; Greenberg, C.R.; Del Bigio, M.R. Neuropathological, biochemical and molecular findings in a glutaric acidemia type 1 cohort. Brain: J. Neurol. 2005, 128, 711-722.

20. Harting, I.; Neumaier-Probst, E.; Seitz, A.; Maier, E.M.; Assmann, B.; Baric, I.; Troncoso, M.; Muhlhausen, C.; Zschocke, J.; Boy, N.P.; et al. Dynamic changes of striatal and extrastriatal abnormalities in glutaric aciduria type i. Brain: J. Neurol. 2009, 132, 1764-1782.

21. Kyllerman, M.; Skjeldal, O.; Christensen, E.; Hagberg, G.; Holme, E.; Lonnquist, T.; Skov, L.; Rotwelt, T.; von Dobeln, U. Long-term follow-up, neurological outcome and survival rate in 28 nordic patients with glutaric aciduria type 1. Eur. J. Paediatr. Neurol.: EJPN: Off. J. Eur. Paediatr. Neurol. Soc. 2004, 8, 121-129. 
22. Garbade, S.F.; Greenberg, C.R.; Demirkol, M.; Gokcay, G.; Ribes, A.; Campistol, J.; Burlina, A.B.; Burgard, P.; Kölker, S. Unravelling the complex mri pattern in glutaric aciduria type i using statistical models-a cohort study in 180 patients. J. Inherit. Metab. Dis. 2014, 37, 763-773.

23. Pollitt, R.J.; Green, A.; McCabe, C.J.; Booth, A.; Cooper, N.J.; Leonard, J.V.; Nicholl, J.; Nicholson, P.; Tunaley, J.R.; Virdi, N.K. Neonatal screening for inborn errors of metabolism: Cost, yield and outcome. Health Technol. Assess. 1997, 1, i-iv, 1-202.

24. Thomason, M.J.; Lord, J.; Bain, M.D.; Chalmers, R.A.; Littlejohns, P.; Addison, G.M.; Wilcox, A.H.; Seymour, C.A. A systematic review of evidence for the appropriateness of neonatal screening programmes for inborn errors of metabolism. J. Public Health Med. 1998, 20, 331-343.

25. American College of Medical Genetics Newborn Screening Expert, G. Newborn screening: Toward a uniform screening panel and system-executive summary. Pediatrics 2006, 117, S296-S307.

26. Loeber, J.G.; Burgard, P.; Cornel, M.C.; Rigter, T.; Weinreich, S.S.; Rupp, K.; Hoffmann, G.F.; Vittozzi, L. Newborn screening programmes in Europe; arguments and efforts regarding harmonization. Part 1. From blood spot to screening result. J. Inherit. Metab. Dis. 2012, 35, 603-611.

27. Wilson, J.M.; Jungner, Y.G. [principles and practice of mass screening for disease]. Bol. Oficina Sanit. Panam. Pan Am. Sanit. Bur. 1968, 65, 281-393.

28. Bjugstad, K.B.; Goodman, S.I.; Freed, C.R. Age at symptom onset predicts severity of motor impairment and clinical outcome of glutaric acidemia type 1. J. Pediatr. 2000, 137, 681-686.

29. Hoffmann, G.F.; Athanassopoulos, S.; Burlina, A.B.; Duran, M.; de Klerk, J.B.; Lehnert, W.; Leonard, J.V.; Monavari, A.A.; Muller, E.; Muntau, A.C.; et al. Clinical course, early diagnosis, treatment, and prevention of disease in glutaryl-coa dehydrogenase deficiency. Neuropediatrics 1996, 27, 115-123.

30. Collins, J.; Leonard, J.V. Natural history of glutaric aciduria type 1. Arch. Dis. Child. 2000, 83, 87.

31. Christensen, E.; Ribes, A.; Merinero, B.; Zschocke, J. Correlation of genotype and phenotype in glutaryl-coa dehydrogenase deficiency. J. Inherit. Metab. Dis. 2004, 27, 861-868.

32. Sauer, S.W.; Okun, J.G.; Fricker, G.; Mahringer, A.; Muller, I.; Crnic, L.R.; Muhlhausen, C.; Hoffmann, G.F.; Horster, F.; Goodman, S.I.; et al. Intracerebral accumulation of glutaric and 3-hydroxyglutaric acids secondary to limited flux across the blood-brain barrier constitute a biochemical risk factor for neurodegeneration in glutaryl-coa dehydrogenase deficiency. J. Neurochem. 2006, 97, 899-910.

33. Sauer, S.W.; Opp, S.; Mahringer, A.; Kaminski, M.M.; Thiel, C.; Okun, J.G.; Fricker, G.; Morath, M.A.; Kölker, S. Glutaric aciduria type $i$ and methylmalonic aciduria: Simulation of cerebral import and export of accumulating neurotoxic dicarboxylic acids in in vitro models of the blood-brain barrier and the choroid plexus. Biochim. Biophys. Acta 2010, 1802, 552-560.

34. Külkens, S.; Harting, I.; Sauer, S.; Zschocke, J.; Hoffmann, G.F.; Gruber, S.; Bodamer, O.A.; Kölker, S. Late-onset neurologic disease in glutaryl-coa dehydrogenase deficiency. Neurology 2005, 64, 2142-2144.

35. Neumaier-Probst, E.; Harting, I.; Seitz, A.; Ding, C.; Kölker, S. Neuroradiological findings in glutaric aciduria type i (glutaryl-coa dehydrogenase deficiency). J. Inherit. Metab. Dis. 2004, 27, 869-876. 
36. Twomey, E.L.; Naughten, E.R.; Donoghue, V.B.; Ryan, S. Neuroimaging findings in glutaric aciduria type 1. Pediatr. Radiol. 2003, 33, 823-830.

37. Herskovitz, M.; Goldsher, D.; Sela, B.A.; Mandel, H. Subependymal mass lesions and peripheral polyneuropathy in adult-onset glutaric aciduria type i. Neurology 2013, 81, 849-850.

38. Kölker, S.; Valayannopoulos, V.; Burlina, A.; Sykut-Cegielska, J.; Wijburg, F.A.; Leão Teles, E.; Zeman, J.; Dionisi-Vici, C.; Barić, I.; Karall, D.; et al. The phenotypic spectrum of organic acidurias and urea cycle disorders. Part 2: The evolving clinical phenotype. J. Inherit. Metab. Dis. 2015, doi:10.1007/s10545-015-9840-x.

39. Rinaldo, P.; Cowan, T.M.; Matern, D. Acylcarnitine profile analysis. Genet. Med.: Off. J. Am. Coll. Med. Genet. 2008, 10, 151-156.

40. Chace, D.H.; Kalas, T.A.; Naylor, E.W. Use of tandem mass spectrometry for multianalyte screening of dried blood specimens from newborns. Clin. Chem. 2003, 49, 1797-1817.

41. Zytkovicz, T.H.; Fitzgerald, E.F.; Marsden, D.; Larson, C.A.; Shih, V.E.; Johnson, D.M.; Strauss, A.W.; Comeau, A.M.; Eaton, R.B.; Grady, G.F. Tandem mass spectrometric analysis for amino, organic, and fatty acid disorders in newborn dried blood spots: A two-year summary from the new england newborn screening program. Clin. Chem. 2001, 47, 1945-1955.

42. Heringer, J.; Boy, S.P.; Ensenauer, R.; Assmann, B.; Zschocke, J.; Harting, I.; Lucke, T.; Maier, E.M.; Muhlhausen, C.; Haege, G.; et al. Use of guidelines improves the neurological outcome in glutaric aciduria type i. Ann. Neurol. 2010, 68, 743-752.

43. Kölker, S.; Christensen, E.; Leonard, J.V.; Greenberg, C.R.; Boneh, A.; Burlina, A.B.; Burlina, A.P.; Dixon, M.; Duran, M.; Garcia Cazorla, A.; et al. Diagnosis and management of glutaric aciduria type i--revised recommendations. J. Inherit. Metab. Dis. 2011, 34, 677-694.

44. Moore, T.; le, A.; Cowan, T.M. An improved lc-ms/ms method for the detection of classic and low excretor glutaric acidemia type 1. J. Inherit. Metab. Dis. 2012, 35, 431-435.

45. Lindner, M.; Ho, S.; Fang-Hoffmann, J.; Hoffmann, G.F.; Kölker, S. Neonatal screening for glutaric aciduria type i: Strategies to proceed. J. Inherit. Metab. Dis. 2006, 29, 378-382.

46. Gallagher, R.C.; Cowan, T.M.; Goodman, S.I.; Enns, G.M. Glutaryl-coa dehydrogenase deficiency and newborn screening: Retrospective analysis of a low excretor provides further evidence that some cases may be missed. Mol. Genet. Metab. 2005, 86, 417-420.

47. Napolitano, N.; Wiley, V.; Pitt, J.J. Pseudo-glutarylcarnitinaemia in medium-chain acyl-coa dehydrogenase deficiency detected by tandem mass spectrometry newborn screening. J. Inherit. Metab. Dis. 2004, 27, 465-471.

48. Hennermann, J.B.; Roloff, S.; Gellermann, J.; Gruters, A.; Klein, J. False-positive newborn screening mimicking glutaric aciduria type i in infants with renal insufficiency. J. Inherit. Metab. Dis. 2009, 32 (Suppl. 1), S355-S359.

49. Crombez, E.A.; Cederbaum, S.D.; Spector, E.; Chan, E.; Salazar, D.; Neidich, J.; Goodman, S. Maternal glutaric acidemia, type i identified by newborn screening. Mol. Genet. Metab. 2008, 94 , $132-134$.

50. Garcia, P.; Martins, E.; Diogo, L.; Rocha, H.; Marcao, A.; Gaspar, E.; Almeida, M.; Vaz, C.; Soares, I.; Barbot, C.; et al. Outcome of three cases of untreated maternal glutaric aciduria type i. Eur. J. Pediatr. 2008, 167, 569-573. 
51. Monavari, A.A.; Naughten, E.R. Prevention of cerebral palsy in glutaric aciduria type 1 by dietary management. Arch. Dis. Child. 2000, 82, 67-70.

52. Bijarnia, S.; Wiley, V.; Carpenter, K.; Christodoulou, J.; Ellaway, C.J.; Wilcken, B. Glutaric aciduria type i: Outcome following detection by newborn screening. J. Inherit. Metab. Dis. 2008, 31, 503-507.

53. Boneh, A.; Beauchamp, M.; Humphrey, M.; Watkins, J.; Peters, H.; Yaplito-Lee, J. Newborn screening for glutaric aciduria type $\mathrm{i}$ in victoria: Treatment and outcome. Mol. Genet. Metab. 2008, 94, 287-291.

54. Mushimoto, Y.; Fukuda, S.; Hasegawa, Y.; Kobayashi, H.; Purevsuren, J.; Li, H.; Taketani, T.; Yamaguchi, S. Clinical and molecular investigation of 19 japanese cases of glutaric acidemia type 1. Mol. Genet. Metab. 2011, 102, 343-348.

55. Strauss, K.A.; Brumbaugh, J.; Duffy, A.; Wardley, B.; Robinson, D.; Hendrickson, C.; Tortorelli, S.; Moser, A.B.; Puffenberger, E.G.; Rider, N.L.; et al. Safety, efficacy and physiological actions of a lysine-free, arginine-rich formula to treat glutaryl-coa dehydrogenase deficiency: Focus on cerebral amino acid influx. Mol. Genet. Metab. 2011, 104, 93-106.

56. Viau, K.; Ernst, S.L.; Vanzo, R.J.; Botto, L.D.; Pasquali, M.; Longo, N. Glutaric acidemia type 1: Outcomes before and after expanded newborn screening. Mol. Genet. Metab. 2012, 106, 430-438.

57. Lee, C.S.; Chien, Y.H.; Peng, S.F.; Cheng, P.W.; Chang, L.M.; Huang, A.C.; Hwu, W.L.; Lee, N.C. Promising outcomes in glutaric aciduria type i patients detected by newborn screening. Metab. Brain Dis. 2013, 28, 61-67.

58. Couce, M.L.; Lopez-Suarez, O.; Boveda, M.D.; Castineiras, D.E.; Cocho, J.A.; Garcia-Villoria, J.; Castro-Gago, M.; Fraga, J.M.; Ribes, A. Glutaric aciduria type i: Outcome of patients with earlyversus late-diagnosis. Eur. J. Paediatr. Neurol.: EJPN: Off. J. Eur. Paediatr. Neurol. Soc. 2013, 17, 383-389.

59. Kölker, S.; Christensen, E.; Leonard, J.V.; Greenberg, C.R.; Burlina, A.B.; Burlina, A.P.; Dixon, M.; Duran, M.; Goodman, S.I.; Koeller, D.M.; et al. Guideline for the diagnosis and management of glutaryl-coa dehydrogenase deficiency (glutaric aciduria type i). J. Inherit. Metab. Dis. 2007, $30,5-22$.

60. Beauchamp, M.H.; Boneh, A.; Anderson, V. Cognitive, behavioural and adaptive profiles of children with glutaric aciduria type i detected through newborn screening. J. Inherit. Metab. Dis. 2009, 32 (Suppl. 1), S207-S213.

61. Hsieh, C.T.; Hwu, W.L.; Huang, Y.T.; Huang, A.C.; Wang, S.F.; Hu, M.H.; Chien, Y.H. Early detection of glutaric aciduria type i by newborn screening in taiwan. J. Formos. Med. Assoc. $=$ Taiwan yi zhi 2008, 107, 139-144.

62. Kölker, S.; Boy, S.P.; Heringer, J.; Muller, E.; Maier, E.M.; Ensenauer, R.; Muhlhausen, C.; Schlune, A.; Greenberg, C.R.; Koeller, D.M.; et al. Complementary dietary treatment using lysinefree, arginine-fortified amino acid supplements in glutaric aciduria type i-a decade of experience. Mol. Genet. Metab. 2012, 107, 72-80.

63. Sauer, S.W.; Opp, S.; Hoffmann, G.F.; Koeller, D.M.; Okun, J.G.; Kölker, S. Therapeutic modulation of cerebral l-lysine metabolism in a mouse model for glutaric aciduria type i. Brain: J. Neurol. 2011, 134, 157-170. 
64. Sauer, S.W.; Opp, S.; Komatsuzaki, S.; Blank, A.; Mittelbronn, M.; Burgard, P.; Koeller, D.M.; Okun, J.G.; Kölker, S. Multifactorial modulation of susceptibility to 1-lysine in an animal model of glutaric aciduria type i. Biochim. Biophys. Acta 2015, 1852, 768-777.

65. Zinnanti, W.J.; Lazovic, J.; Housman, C.; LaNoue, K.; O’Callaghan, J.P.; Simpson, I.; Woontner, M.; Goodman, S.I.; Connor, J.R.; Jacobs, R.E.; et al. Mechanism of age-dependent susceptibility and novel treatment strategy in glutaric acidemia type i. J. Clin. Investig. 2007, 117, 3258-3270.

66. Pfeil, J.; Listl, S.; Hoffmann, G.F.; Kölker, S.; Lindner, M.; Burgard, P. Newborn screening by tandem mass spectrometry for glutaric aciduria type 1: A cost-effectiveness analysis. Orphanet J. Rare Dis. 2013, 8, 167.

(C) 2015 by the authors; licensee MDPI, Basel, Switzerland. This article is an open access article distributed under the terms and conditions of the Creative Commons Attribution license (http://creativecommons.org/licenses/by/4.0/). 